\title{
BM Global Health Using the COVID-19 pandemic to reimagine global health teaching in high-income countries
}

\author{
Salla Atkins, ${ }^{1,2}$ Ananya Tina Banerjee, ${ }^{3}$ Kathleen Bachynski, ${ }^{4}$ Amrita Daftary (D) , 5,6 \\ Gauri Desai, ${ }^{7}$ Aeyal Gross, ${ }^{8}$ Bethany Hedt-Gauthier, ${ }^{9}$ Emily Mendenhall, ${ }^{10}$ \\ Benjamin Mason Meier, ${ }^{11,12}$ Stephanie A Nixon, ${ }^{13}$ Ann Nolan, ${ }^{14}$ Tia M Palermo, ${ }^{7}$ \\ Alexandra Phelan, ${ }^{15}$ Oksana Pyzik, ${ }^{16}$ Pamela Roach, ${ }^{17}$ Thurka Sangaramoorthy, ${ }^{18}$ \\ Claire J. Standley, ${ }^{15}$ Gavin Yamey (D) , ${ }^{19}$ Seye Abimbola (D) , ${ }^{20}$ Madhukar Pai (D) ${ }^{21}$
}

To cite: Atkins S, Banerjee AT, Bachynski $\mathrm{K}$, et al. Using the COVID-19 pandemic to reimagine global health teaching in high-income countries. BMJ Global Health 2021;6:e005649. doi:10.1136/ bmjgh-2021-005649

Received 8 March 2021 Accepted 11 March 2021

Check for updates

(c) Author(s) (or their employer(s)) 2021. Re-use permitted under CC BY-NC. No commercial re-use. See rights and permissions. Published by BMJ.

For numbered affiliations see end of article.

Correspondence to Dr Madhukar Pai; madhukar.pai@mcgill.ca

\section{INTRODUCTION}

The COVID-19 pandemic has changed how we live, work and communicate. Global health teaching is no exception. Across universities, professors like us have had to quickly redesign our courses, and deliver them virtually, even as the pandemic continues to bring new challenges every day. Out of that struggle, new learning opportunities have emerged.

This editorial, coauthored by 20 professors in seven high-income countries (HICs), aims to synthesise our learnings and insights from over 25 courses we taught (or are currently teaching). ${ }^{1}$ We acknowledge upfront that our insights might not transfer to global health teaching in all contexts, especially in settings where the digital divide is worsening educational inequities. We hope to learn from similar articles on how our colleagues in low/middle-income countries (LMICs) have adapted and innovated with their teaching during this crisis.

Our collective experience suggests that despite the pandemic chaos and fatigue, global health teaching can be improved (box 1) by using COVID-19 as a teachable moment to focus on equity and human rights as a central theme, and by integrating anti-racism and anti-oppression as core content and orientation in our curriculum. The online format allows instructors to centre voices from the Global South, Indigenous scholars, and individuals with lived experience of oppression and resilience. Remote teaching also helps us reach wider and diverse audiences, including groups that may not be enrolled in traditional degree programmes. Learning from COVID19 , which is widening disparities within and across countries, global health teaching must educate students to address health disparities wherever they occur, not just in LMICs. While the online format offers many challenges, we believe there are ways to increase student engagement and reduce fatigue (box 2).

\section{USE COVID-19 AS A TEACHABLE MOMENT}

Even before the pandemic, students in HICs have shown great interest in global health. ${ }^{2}$ However, over the last year, we see that student interest in global health has increased significantly. The pandemic is a powerful example to illustrate health interdependence, the need for transnational efforts and global solidarity, ${ }^{3}$ and the systemic barriers to achieving solidarity. ${ }^{4}$ It provides a superb example to demonstrate how equity and human rights are a core concern in global health. As the COVID-19 situation evolves, each class provides an opportunity to break down in real time how inequities are magnified in times of crisis. Indeed, global health professors now have mountains of new material that can be used to illustrate health inequities within and between nations, social determinants of health, global health governance, vaccine nationalism, market failures, and the inseparable link between politics, law, economics and pandemics.

The fact that a handful of HICs have monopolised a huge share of the COVID-19 vaccines is a stark indication of the persistent power asymmetry that permeates all aspects of global health, ${ }^{56}$ and how existing political and economic structures can be used to exacerbate privilege further. ${ }^{7}$

Global health itself needs to be reimagined during this crisis, and global health education must use this crisis as a teachable moment for 
Box 1 Adapting content and scope of global health teaching during the pandemic

- Use COVID-19 as a teachable moment, and use it to focus on equity and human rights as a central theme in global health.

- Cover the importance of understanding racism and white supremacy in global health, and include content on privilege, antioppression, anti-racism and allyship.

- Include content on coloniality in global health and the persistent power asymmetries that affect every aspect of global health.

- Decolonise pedagogy as a means of contributing to ongoing efforts towards inclusivity in academia.

- Centre the courses, where possible, on Black, Indigenous and people of colour speakers, especially experts from the Global South, Indigenous scholars, and individuals working and living within their impacted communities.

- Teach students to see and address health inequities wherever they occur, not just in low-income countries.

- Diversify the audience and allow more people to access course content remotely, where universities permit this.

\section{Box 2 Tips and best practices for online teaching}

- Begin the class with a short check-in and ask students how they are are doing to show you care about them; talk to students about mental health, stress and burnout, and anticipate student and teacher fatigue.

- Relax attendance requirements (especially if students are in different time zones); expect and accept attrition during the live sessions.

- Cut back on assignments and examinations; reduce the volume of readings and use shorter rather than longer articles.

- Avoid long sessions (eg, 3 hours of class time) and incorporate more breaks in all length classes.

- Reduce didactic lectures, make them shorter, and use a combination of live and recorded lectures; use the flipped classroom model with recorded lectures made available in advance, and use the class time for student questions and discussions.

- Alternate synchronous with asynchronous sessions (to address Zoom fatigue).

- Use break-out groups and short student-led presentations to enhance student interactions and participation.

- Use audience polls, interactive tools and social media.

- Offer accessible office hours (flexible times for support) and engage teaching assistants to enhance student contact.

- Assign multimodal content (eg, videos, films, podcasts, webinars, music, spoken word) as an alternative to required readings or books (but ensure this time is counted towards the overall effort/time).

- Be more lenient and kinder with grading; establish no detriment policy towards grading.

- Forego rigid, examination-style assignments in favour of shorter, interactive assignments and open-book examinations; prefer essays and short answers over fact-based, multiple choice questions.

- Eliminate late policies and graded participation, while offering rolling deadlines, to provide students with flexibility while navigating this crisis.

- Offer an honorarium to guest speakers, especially speakers from low/middle-income countries.

Do not set impossible expectations for students or teachers during this crisis. future leaders to implement these changes. The pandemic's wide-reaching impact has spurred commensurate wide-reaching interest, including education. Today, we have students from many disciplines showing an interest in global health, attending our lectures. This can facilitate integration of a transdisciplinary lens into our teaching. Our teaching must frame global health inequities, problems, and solutions within the broader context of global governance, economic, legal and political drivers of inequality, and historical context (eg, colonialism, slavery, imperialism, structural adjustment, capitalism).

Indeed, all of us have used COVID-19 examples and found our students to be very responsive to topical issues, particularly as many of our students are joining virtually from all parts of the world and can draw direct comparison with each other's lived experience of COVID-19. To that end, COVID-19 also provides an opportunity to showcase the different ways in which HICs could learn from LMICs, and how LMICs and HICs can learn from their COVID-19 response to reimagine their healthcare systems. ${ }^{89}$ It has been a humbling experience for countries like the USA and UK that often advised other governments on outbreak response to see large numbers of COVID-19 cases and deaths. HICs can learn a lot from successful Asia-Pacific responses to COVID-19. ${ }^{10}$

\section{INCLUDE ANTI-RACISM, EQUITY AND DIVERSITY AS CORE CONTENT}

The year 2020 was a year of racial reckoning, and we know racism pervades all aspects of medicine and society. Global health is neither global nor diverse, and racism and white supremacy are major issues in global health that continue to drive population and individual-level health inequities. ${ }^{6} 1112$ Global health is delivered by women and led by men, with HICs dominating every aspect of global health. ${ }^{13}$ Research has shown a profound need for ongoing anti-oppression and allyship training among future public health and global health students and professionals. ${ }^{14}$ This need is urgent in the context of COVID-19, decolonisation efforts and Black Lives Matter.

Some of our courses included content on privilege, antioppression, anti-racism and allyship. ${ }^{15}$ Such sessions can be impactful and set the tone for the rest of the course. In fact, we would argue that all global health courses must include content on privilege, anti-oppression and allyship, informed by anti-colonial and critical race theory, as well as intersectionality. This is because our global and public health education system reinforces the same inequities it was designed to overcome. Learning about oppression that includes racism-specifically how certain groups are disadvantaged and disproportionately impacted by the public health system, and how professors, as embedded in the system, can unconsciously and sometimes consciously misuse our power and privilege when working with vulnerable communities-is therefore key to disrupting the marginalisation of these groups and to integrate anti-oppression and anti-racism into practice 
in global health. ${ }^{14}$ Indeed, every global health educator must actively contemplate and address their complicity in the very systems of inequality that cause health disparities. This includes but is not limited to understanding one's implicit (and explicit) biases. Given the plethora of training opportunities now available in our institutions, there is no excuse against availing of the opportunity.

Anti-racism teaching and action in health systems and education is urgently needed, especially as we see health inequities exacerbated by the pandemic. ${ }^{16}$ While there are encouraging shifts, we hope people will continue to give importance to health and social equity after the pandemic when everyone will rush to get back to 'normal' or a doubling down on securitising global health. Issues around diversity, equity and inclusion, understood using an intersectional anti-oppression approach must, therefore become core content in global health courses.

\section{DECOLONISING PEDAGOGY IN GLOBAL HEALTH}

Calls to decolonise global health ${ }^{6} 1718$ apply equally to global health education. This includes global health courses that need to become more critical, reflexive and go beyond the apolitical narratives that are commonly taught in HICs. Introductory courses, in particular, should begin with content on the colonial history of global health and the coloniality that still persists internationally. While global health often turns its gaze elsewhere, we must also recognise the ongoing colonisation in our own HICs and work to dismantle that with the same commitment in order to improve population-level health.

Indeed, several schools in many HICs have hosted conferences, courses and webinars on decolonising global health. ${ }^{17}$ This theme is becoming a mainstream issue, even if the term is increasingly misused or misinterpreted, ${ }^{19}$ and largely centred on privileged institutions and people in the Global North. ${ }^{20} 21$

Global health teachers in HICs could aspire to decolonise their pedagogy as a means of contributing to ongoing efforts towards inclusivity in academia. ${ }^{22}$ To achieve this, global health courses must prioritise voices from the Global South, Indigenous scholars, and individuals working and living within their impacted communities. They must empower students to connect their personal experiences to concepts and theories that they are learning in class.

Decolonised pedagogy is distinct from other forms of critical pedagogy in its commitment to centring Indigenous and marginalised ways of knowing and understanding the world, as well as a dedication to addressing and dismantling the harmful legacies of colonial and imperial powers. ${ }^{22}$

We can centre our courses on Black, Indigenous and people of colour speakers, especially experts from the Global South. They can elevate our courses with their authenticity, credibility and lived experience. The pandemic and the concomitant explosion in online tools for teaching and collaboration have shown us that this is possible without burdening the environment. We acknowledge this might be difficult in courses that are taught by single professors, but even here, it is always possible to assign readings and videos that reflect diverse perspectives.

Many of us have used the online format to invite speakers from around the world into our virtual classrooms, with great impact. A large proportion of the impact came from the diversity and representation afforded by engaging with truly global leaders; this is difficult to achieve through in-person instruction due to budget constraints and travel required.

The initial work in setting up an online course is significant. However, the opportunity for greater creativity, global inclusion of diverse speakers and facilitating peer-to-peer discussion for a debate (eg, LMIC students comparing and contrasting their experiences with students in HICs) has helped to bring a livelier dimension despite the challenges of Zoom fatigue.

\section{GLOBAL HEALTH MUST INCLUDE LOCAL}

Typically, global health courses in HICs focus on inequities between HICs and LMICs. But many HICs handled COVID-19 poorly, and the inequities within HICs were exposed. ${ }^{8}$ So, global health education must teach students to address health disparities wherever they occur to avoid reinforcing a sense of the 'other'. This can provide an opportunity to discuss the threat of populist nationalism to global health. We must also understand that faculty and students have histories and ongoing experiences of marginalisation. Through exposure to case studies, multimodal content and local leaders, students' critical consciousness can be raised to recognise and problematise situations of systemic injustices that prevail in their midst, along the intersecting lines of race, ethnicity, language, religion, legal status, gender, ability and sexual orientation.

For courses set in the Canadian, Australian and US context, for example, we need to include extensive discussions on settler colonialism, and its ongoing impact on the health of Indigenous peoples and racialised groups. ${ }^{23} 24$ For global health courses in the USA and Canada, in addition, it is critical to discuss the history of the transatlantic slave trade and its legacy of anti-Black racism within and beyond healthcare. Curricula need to be contextually specific, such as the history of 'redlining' in the USA, a process by which the government and private sector systematically denied services to residents of certain areas based on their race, contributing to the profound health disparities we see today. In Europe, many schools of hygiene, tropical medicine and public health are grappling with their own colonial legacies and must open spaces within courses for such discussions of how these histories continue to play out in present-day global health practice, education and research. ${ }^{25}$ For all of these settings, we must expressly address the racism and systemic violence against immigrants and visible minorities (including in our 
classrooms), and how government responses can perpetuate stigma, discrimination and violence during a crisis.

\section{DIVERSIFYING OUR AUDIENCE}

Diversity of students is another area where global health education must do better. Currently, global health degrees are concentrated in HICs, and are expensive and inaccessible for most students from the Global South. ${ }^{2}$

Some of us could open our online courses to international participants, while others taught courses explicitly aimed at professionals in LMICs (eg, public health practitioners and journalists). The online format allowed us to teach groups that we might not normally see in our HIC classrooms. Poor internet connectivity, however, was one of the big challenges, and might worsen inequities by favouring participants in big cities and middle-income countries.

Some of us live-streamed our courses on YouTube to reach a broader audience, and this resulted in substantial re-viewing and access after the course ended. It will be impactful if more global health instructors could share their course materials and videos online, and contribute to democratising global health education. There is little cost to doing this, and the explosion of webinars illustrates the scalability of online education. There is a need, however, to curate and classify global health videos, courses and webinars, and create a repository that is easy to access and search. Currently, there are crowd-sourced, curated collections of global health books ${ }^{26}$ and films, ${ }^{27}$ but they do not cover online course materials.

\section{BEST PRACTICES FOR ONLINE TEACHING}

Pandemic fatigue has made us all more stressed and less productive. Students, in particular, are struggling with loneliness and mental health issues. ${ }^{28}$ Teachers need to factor this in, while using their public health knowledge to keep their students safe during these challenging times.

Teachers are struggling too, especially women academics, ${ }^{29}$ and we need to be open with students about our own struggles.Juggling work, childcare and the stress of family members and friends getting COVID-19 can be tough. Students understand this. In addition, teaching on the pandemic itself can be stressful or upsetting to students and faculty, and information for accessing support services should be made easily accessible.

While online teaching brings Zoom fatigue, lack of personal interactions and challenges with students scattered across many time zones, professors have tried many approaches to make it work. ${ }^{30}$ Box 2 includes a list of tips and best practices, based on our collective experience. ${ }^{1}$ Some of them necessitate institutional supports (eg, additional teaching assistant hours or funding to provide honoraria) but most of them can be independently operationalised. Many of these were spurred by the shift to online teaching and the COVID-19 pandemic, but should be considered for courses even after the pandemic.

In summary, as the pandemic threatens to stretch through 2021, teachers and students have a tough year ahead. We believe kindness, empathy and self-compassion are critical for students' and professors' wellness during these difficult times and to ensure we fully support the development of all students in the pipeline for the global health practice, policy, and research.

\section{Author affiliations}

${ }^{1}$ New Social Research and Faculty of Social Sciences, Tampere University, Tampere, Pirkanmaa, Finland

${ }^{2}$ Department of Global Public Health, Karolinska Institute, Stockholm, Stockholm County, Sweden

${ }^{3}$ School of Population and Global Health, McGill University Montreal, Montreal, Quebec, Canada

${ }^{4}$ Public Health Program, Muhlenberg College, Allentown, Pennsylvania, USA ${ }^{5}$ Dahdaleh Institute of Global Health Research, York University, Toronto, Ontario, Canada

${ }^{6}$ CAPRISA, Durban, South Africa

${ }^{7}$ Department of Epidemiology and Environmental Health, University at Buffalo, The State University of New York, Buffalo, New York, USA

${ }^{8}$ Faculty of Law, Tel Aviv University, Tel Aviv, Israel

${ }^{9}$ Department of Global Health and Social Medicine, Harvard Medical School, Boston, Massachusetts, USA

${ }^{10}$ Edmund A Walsh School of Foreign Service, Georgetown University, Washington, District of Columbia, USA

${ }^{11}$ Department of Public Policy, University of North Carolina at Chapel Hill, Chapel Hill, North Carolina, USA

${ }^{12} 0$ 'Neill Institute for National and Global Health Law, Georgetown University, Washington, DC, USA

${ }^{13}$ Department of Physical Therapy, University of Toronto, Toronto, Ontario, Canada

${ }^{14}$ Trinity Centre for Global Health, Trinity College Dublin, Dublin, Ireland

${ }^{15}$ Center for Global Health Science and Security, Georgetown University, Washington, District of Columbia, USA

${ }^{16}$ School of Pharmacy, University College London, London, UK

${ }^{17}$ Departments of Family Medicine and Community Health Sciences, University of Calgary, Calgary, Alberta, Canada

${ }^{18}$ Department of Anthropology, University of Maryland, College Park, Maryland, USA

${ }^{19}$ Duke Global Health Institute, Duke University, Durham, North Carolina, USA

${ }^{20}$ School of Public Health, University of Sydney, Sydney, New South Wales, Australia

${ }^{21}$ School of Population and Global Health, McGill University, Montreal, Quebec, Canada

Twitter Salla Atkins @SallaAtkins, Ananya Tina Banerjee @ananya_tb, Kathleen Bachynski @bachyns, Amrita Daftary @DaftaryAmrita, Aeyal Gross @AeyalGross, Bethany Hedt-Gauthier @BHedtGauthier, Emily Mendenhall @mendenhall_em, Benjamin Mason Meier @BenjaminMMeier, Stephanie A Nixon@sanixto, Ann Nolan @AnnNolanTCGH, Tia M Palermo @TiaPalermo, Alexandra Phelan @alexandraphelan, Oksana Pyzik @0ksanaPyzikUCL, Pamela Roach@pamelamroach, Thurka Sangaramoorthy @Thurka149, Claire J. Standley @ClaireJStandley, Gavin Yamey @gyamey, Seye Abimbola @seyeabimbola and Madhukar Pai @paimadhu

Acknowledgements This editorial draws on a blog post entitled 'We Can Use The Pandemic To Reimagine Global Health Teaching' in Forbes, published on 15 February 2021.

Contributors MP wrote the initial draft with input from all the coauthors. All authors revised and approved the final version.

Funding The authors have not declared a specific grant for this research from any funding agency in the public, commercial or not-for-profit sectors.

Competing interests SA is EIC of BMJ Global Health, and MP serves on the Editorial Board.

Patient consent for publication Not required.

Provenance and peer review Not commissioned; internally peer reviewed.

Data availability statement There are no data in this work.

Open access This is an open access article distributed in accordance with the Creative Commons Attribution Non Commercial (CC BY-NC 4.0) license, which permits others to distribute, remix, adapt, build upon this work non-commercially, and license their derivative works on different terms, provided the original work is 
properly cited, appropriate credit is given, any changes made indicated, and the use is non-commercial. See: http://creativecommons.org/licenses/by-nc/4.0/.

\section{ORCID iDs}

Amrita Daftary http://orcid.org/0000-0003-2275-3540

Gavin Yamey http://orcid.org/0000-0002-8390-7382

Seye Abimbola http://orcid.org/0000-0003-1294-3850

Madhukar Pai http://orcid.org/0000-0003-3667-4536

\section{REFERENCES}

1 Pai M. We can use the pandemic to Reimagine global health teaching, 2021. Forbes. Available: https://www.forbes.com/sites/ madhukarpai/2021/02/15/we-can-use-the-pandemic-to-reimagineglobal-health-teaching/?sh=70c78a771710 [Accessed 4 Mar 2021].

2 Svadzian A, Vasquez NA, Abimbola S, et al. Global health degrees: at what cost? BMJ Glob Health 2020;5:e003310.

3 Gostin LO, Meier BM. Foundations of Global Health \& Human Rights. Oxford University Press, 2020. Available: https://global.oup. com/academic/product/foundations-of-global-health-and-humanrights-9780197528303?lang=en\&cc=us\#

4 Daftary A, Viens AM. Solidarity in global health Research-Are the stakes equal? Am J Bioeth 2020;20:59-62.

5 Abimbola S. The foreign gaze: authorship in academic global health. BMJ Glob Health 2019;4:e002068.

6 Abimbola S, Pai M. Will global health survive its decolonisation? Lancet 2020;396:1627-8.

7 Phelan AL, Eccleston-Turner M, Rourke M, et al. Legal agreements: barriers and enablers to global equitable COVID-19 vaccine access. Lancet 2020;396:800-2.

8 Dalglish SL. COVID-19 gives the lie to global health expertise. Lancet 2020;395:1189.

9 Saha S, Pai M. Can COVID-19 innovations and systems help lowand middle-income countries to re-imagine healthcare delivery? Med 2021. doi:10.1016/j.medj.2021.02.008. [Epub ahead of print: 03 Mar 2021].

10 Han E, Tan MMJ, Turk E, et al. Lessons learnt from easing COVID-19 restrictions: an analysis of countries and regions in Asia Pacific and Europe. Lancet 2020;396:1525-34.

11 Pai M. Global Health Needs To Be Global \& Diverse, 2020. Forbes. Available: https://www.forbes.com/sites/madhukarpai/2020/03/ 08/global-health-needs-to-be-global-diverse/\#502c7d976590 [Accessed 22 March 2021].

12 Kumar A. White Supremacy in global health, 2020. Available: https:// www.thinkglobalhealth.org/article/white-supremacy-global-health

13 Pai M. Global health research needs more than a Makeover. USA: Forbes, 2019. https://www.forbes.com/sites/madhukarpai/2019/ 11/10/global-health-research-needs-more-than-a-makeover/\# 3c21ddcf7e34

14 Djulus G, Sheikhan NY, Nawaz E, et al. Advancing Allyship through Antioppression workshops for public health students: a mixed methods pilot evaluation. Pedagogy Health Promot 2020:237337992096241.

15 Nixon SA. The coin model of privilege and critical allyship: implications for health. BMC Public Health 2019;19:1637.

16 Bambra C, Riordan R, Ford J, et al. The COVID-19 pandemic and health inequalities. J Epidemiol Community Health 2020;74:964-8.

17 Büyüm AM, Kenney C, Koris $A$, et al. Decolonising global health: if not now, when? BMJ Glob Health 2020;5.

18 Hirsch LA. Is it possible to decolonise global health institutions? Lancet 2021;397:189-90.

19 Khan T. Decolonisation is a comfortable buzzword for the aid sector, 2021. Available: https://www.opendemocracy.net/en/decolonisationcomfortable-buzzword-aid-sector/ [Accessed 22 March 2021].

20 Louskieter L, Munshi S. Global Health is still the "Master's House": how brave are we to decolonise and dismantle it? 2020. Available: https://www.internationalhealthpolicies.org/featured-article/globalhealth-is-still-the-masters-house-how-brave-are-we-to-decoloniseand-dismantle-it/ [Accessed 22 March 2021]

21 Tuck E, Yang KW. Decolonization is not a metaphor. Decolon Ind Edu Soc 2012;1:1-40.

22 Primiano SJ KA, Sangaramoorthy T. Plagues, pathogens, and Pedagogical decolonization: reflecting on the design of a Decolonized pandemic Syllabus. Teach Learn Anthropol J 2020;3:47-60.

23 Richardson L, Crawford A. COVID-19 and the decolonization of Indigenous public health. CMAJ 2020;192:E1098-100.

24 Bond CJ, Singh D. More than a refresh required for closing the gap of Indigenous health inequality. Med J Aust 2020;212:198-9.

25 Erondu NA, Peprah D, Khan MS. Can schools of global public health dismantle colonial legacies? Nat Med 2020;26:1504-5.

26 Pai M. If you had to read one book on global health. nature microbiology community, 2018. Available: https://naturemicrobiolo gycommunity.nature.com/posts/41300-if-you-had-to-read-onebook-on-global-health [Accessed 4 Mar 2021].

27 Pai M. Inspiring global health films. nature microbiology community, 2020. Available: https://naturemicrobiologycommunity.nature.com/ posts/inspiring-global-health-films [Accessed 4 Mar 2021].

28 Son C, Hegde S, Smith A, et al. Effects of COVID-19 on college students' mental health in the United States: interview survey study. J Med Internet Res 2020;22:e21279.

29 Gabster BP, van Daalen K, Dhatt R, et al. Challenges for the female academic during the COVID-19 pandemic. Lancet 2020;395:1968-70.

30 Hawks SR, Judd HA. Excellence in the design and delivery of an online global health survey course: a roadmap for educators. Pedagogy Health Promot 2020;6:70-6. 